\title{
Capsule Commentary on Duan-Porter et al., Control Beliefs and Risk for Death, Stroke and Myocardial Infarction in Middle-aged and Older Adults: An Observational Study
}

\author{
Jeffrey L. Jackson, MD, MPH \\ Division of General Internal Medicine, Zablocki VAMC, Milwaukee, WI, USA.
}

J Gen Intern Med 30(8):1189

DOI: $10.1007 / \mathrm{s} 11606-015-3340-4$

(c) Society of General Internal Medicine 2015

667 here is more in heaven and earth than is dreamt of in your philosophy." Dualism, the separation of the mind from the body has pervaded western thought; its roots can be traced from Plato through Descartes and into modern medical textbooks. Duan-Porter and colleagues explored the relationship between control beliefs and health outcomes among US adults. ${ }^{1}$ Among almost 6000 participants, those with greater belief in their control over their health were less likely to have strokes, heart attacks or die, while those with beliefs suggesting more constraints, who were more externally controlled, experienced higher rates. Patients with high control and low constraint beliefs did particularly well.

Those with a more biological frame of reference can explain these results by arguing that health behavior may be linked to health beliefs. ${ }^{2,3}$ Patients with a strong belief in their own control over their health would, presumably, be more likely to exercise or engage in other positive behaviors that would influence their own health outcomes. Patients who feel at the mercy of a capricious universe, who are more fatalistic in their beliefs, may be more pessimistic about the value of healthy behavior.

As Osler said, "the good physician treats the disease; the great physician treats the patient who has the disease." This study suggests that Osler was right, it is important to know the patient as well as the disease. Patients with low self-control and higher sense of external constraints may define a particularly high-risk group for poor health outcomes. It may be possible to tailor approaches based on understanding these beliefs. Patients with higher sense of self-control may respond better to interventions that reinforce these beliefs; for example, emphasizing the importance of diet and exercise. There are a large number of unanswered questions. Are health control beliefs static or fixed traits? Is there a direct link between attitudes and health outcomes or are they mediated by differential health behaviors, such as adherence? Are some types of interventions more (or less) effective, depending on underlying health beliefs? Dualism may need to give way to holism in modern medicine.

Conflict of Interest: The author has no conflict of interest with this article.

Corresponding Author: Jeffrey L. Jackson, MD, MPH; Division of General Internal MedicineZablocki VAMC, Milwaukee, WI, USA (e-mail: jjackson@mcw.edu).

\section{REFERENCES}

1. Duan-Porter W, Hasting SN, Beelon B, Van Houtven CH. Control beliefs and risk for death, stroke and myocardial infarction in middle-aged and older adults: an observational study. J Gen Intern Med. 2015. doi:10.1007/ s11606-015-3275-9.

2. Gherman A, Schnur J, Montgomery G, Sassu R, Veresiu I, David D. How are adherent people more likely to think? A meta-analysis of health beliefs and diabetes self-care. Diabetes Educ. 2011;37(3):392-408. doi:10.1177/ 0145721711403012.

3. Celano CM, Beale EE, Moore sv, Wexler DJ, Huffman JC. Positive psychological characteristics in diabetes: a review. Curr Diab Rep. 2013;13(6):917-929. doi:10.1007/s11892-013-0430-8. 